\title{
Prostaglandins and the maintenance of pregnancy in goats
}

\author{
M. M. Ford, I. R. Young and G. D. Thorburn \\ Department of Physiology, Monash University, Clayton, Victoria 3168, Australia
}

\begin{abstract}
Introduction
It has been proposed that the corpus luteum of pregnancy in goats is maintained by a luteotrophic complex, the components of which change with gestational age, and that prostaglandins may form part of the complex during the last third of gestation (Liggins and Thorburn, 1994). Although it has been known for some time that $\mathrm{PGF}_{2 a}$ is essential for luteolysis in several species including goats, the luteotrophic action of $\mathrm{PGE}_{2}$ has only recently been investigated. $\mathrm{PGE}_{2}$ is the main prostaglandin produced by the goat placenta before term both in vitro (Mitchell et al, 1978) and in vivo (Ford et al., 1992). In sheep, $\mathrm{PGE}_{2}$ can override the luteolytic action of $\mathrm{PGF}_{20}$ (Henderson et al., 1977) and has a direct effect in protecting the pig corpus luteum against luteolysis by $\mathrm{PGF}_{2 \alpha}$ (Ford and Christenson; 1991). Uterine vein concentrations of $\mathrm{PGE}_{2}$ are higher than systemic concentrations and rise steadily with increasing gestational age (Ford et al., 1992). The present experiments were designed to explore the luteotrophic role of prostaglandins in the last third of gestation in goats. Maternal administration of indomethacin, a potent inhibitor of prostaglandin synthetase, caused a significant decrease in progesterone concentrations, suggesting that prostaglandins do provide functional support for the corpus luteum. Moreover, the treated animals came into premature labour, suggesting that a relatively small decrease in progesterone concentrations may trigger the luteolytic process and the initiation of parturition.
\end{abstract}

\section{Materials and Methods}

Ten angora-cross does of known gestational age were used. Twelve hours before surgery, animals were treated with progesterone $\left(1 \mathrm{mg} \mathrm{kg}{ }^{-1} \mathrm{i}, \mathrm{m}\right.$.) as a precaution against post-surgical abortion. Surgery was performed between day 117 and day 119 of gestation under aseptic conditions and following the protocol described by Deayton et al. (1993) for cannulation of the uterine veins, carotid artery and jugular vein. At least 10 days of post-surgical recovery time was allocated before the beginning of the experimental protocol. Patency of uterine vein cannulae was maintained with a continuous infusion of saline containing heparin $\left(50 \mathrm{iu} \mathrm{ml}^{-1}\right)$ at a rate of $1.0 \mathrm{ml} \mathrm{h}^{-1}$.

Six animals received a continuous i.v. (via maternal jugular vein) infusion of indomethacin $\left(5 \mathrm{mg} \mathrm{kg}^{-1}\right.$ day $\left.^{-1}\right)$, between day 132 and day 137 of gestation. Control animals $(n=4)$ underwent identical surgical manipulations, infusion rates of saline vehicle solutions and sampling procedures. Blood samples were collected daily, from the maternal carotid artery and uterine vein cannulae, from day 130 until labour, the designated endpoint of each experiment. At labour, does and fetuses were killed with an overdose of barbiturate (Lethobarb: Amold of Reading Pty Ltd, Boronia, Victoria). On the first day of infusion of indomethacin, blood samples were collected at times $-1,0,1,2,3,6$ and $12 \mathrm{~h}$, with time 0 designated as the start of the infusion. For the analysis of prostaglandins, blood was transferred to an ice-cold tube containing EDTA $\left(1.5 \mathrm{mg} \mathrm{ml}^{-1}\right)$ and indomethacin (10 $\mu \mathrm{mol} \mathrm{I}^{-1}$ whole blood). For the analysis of progesterone, blood was transferred to chilled tubes containing 125 iu lithium heparin. Tubes were centrifuged at $2000 \mathrm{~g}$ for $10 \mathrm{~min}$ at $4^{\circ} \mathrm{C}$. Plasma, for the analysis of $\mathrm{PGE}_{2}$, was first methyloximated by diluting it (ratio I:I) with $0.12 \mathrm{~mol}$ methoxyamine hydrochloride $\mathrm{I}^{-i}$ in sodium acetate buffer (I mol $\left.1^{-1}, \mathrm{pH} 5.0\right)$ containing $10 \%(\mathrm{v} / \mathrm{v})$ absolute ethanol, then incubated overnight at room temperature before freezing at $-20^{\circ} \mathrm{C}$. Plasma to be analysed for $\mathrm{PGF}_{2 \omega^{\prime}}, 13,14$-dihydro-15-keto $\mathrm{PGF}_{2 u}$ (PGFM) and progesterone was frozen at $-20^{\circ} \mathrm{C}$. 


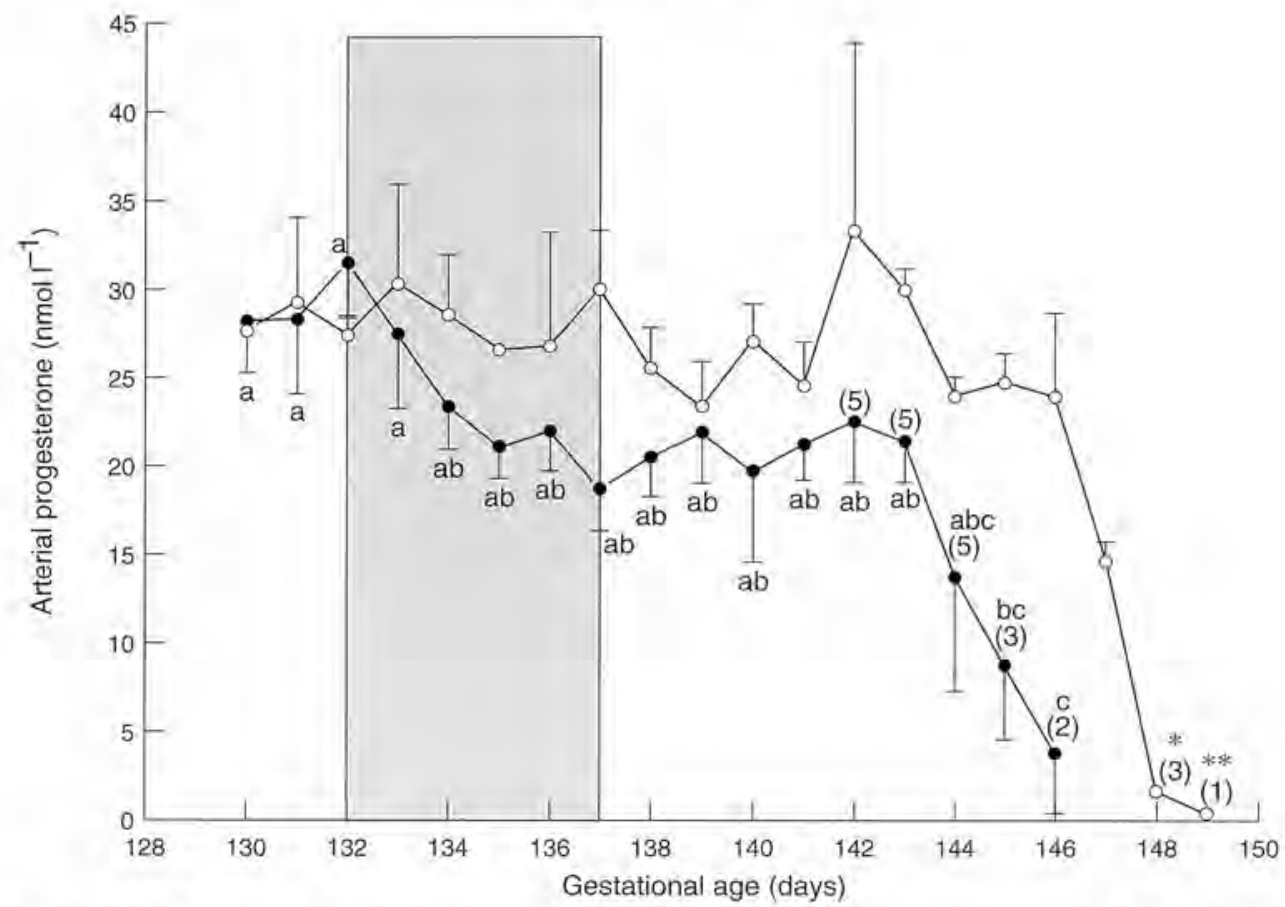

Fig. 1. Arterial plasma concentrations of progesterone in indomethacin- $\bullet, n=6$ except where indicated due to parturition) and vehicle- $(0, n=4$ except where indicated due to parturition) treated animals. Progesterone concentrations on day 137 were significantly different between the two treatment groups (Student's $\left.t_{;} P<0,02\right)$. Values with different letters $(a, b, c)$ or symbols $(*, * *)$ are significantly different $(P<0.05)$. The shaded area between day 132 and day 137 indicates the period of infusion.

Measurement of progesterone and prostaglandins are described by Deayton et al. (1993) (progesterone and $\mathrm{PGE}_{2}$ ) and Burgess et al. (1990) ( $\mathrm{PGF}_{2 \alpha}$ and PGFM). The interassay coefficients of variation, estimated from ten assays (progesterone), seven assays $\left(\mathrm{PGF}_{2 a}\right)$, seven assays $\left(\mathrm{PGE}_{2}\right)$ and nine assays (PGFM) were $19.30 \%, 25.41 \%, 17.53 \%$ and $19.30 \%$, respectively. The intra-assay coefficient of variation for each assay was $12.10 \%$ (progesterone), $14.86 \%\left(\mathrm{PGE}_{2}\right), 11.28 \%\left(\mathrm{PGF}_{20}\right)$ and $6.00 \%$ (PGFM). The sensitivities of the various assays were $4.36 \pm 0.21 \mathrm{nmol}$ progesterone $1^{-1}, 0.27 \pm 0.03 \mathrm{nmol} \mathrm{PGE}_{2} 1^{-1}$,

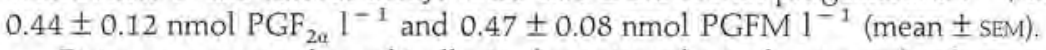

Data are presented graphically in the untransformed state and values are reported as means \pm SEM. Hormone concentrations were first tested for homogeneity of variance by applying Bartlett-Box F and Cochrane's C test. Inhomogeneous data were rendered homogeneous by subjecting them to a square root or $\log$ transformation. A two-way multivariate analysis of variance (ANOVA) was performed from day 130 to term with time and individual animal as the factors analysed. Significant data were further subjected to a Student-Newman-Keuls' (SNK) test for multiple comparisons to identify differences between means. During the infusion (days 132-137), differences in plasma hormone concentrations, gestational age and individual animals were identified by a three-way ANOVA with experimental group, time and individual animals as the factors. Comparisons between group means at specific gestational dates were made using an unpaired Student's $t$ test.

\section{Results}

Arterial plasma progesterone concentrations were not significantly different between the control and indomethacin-treated groups during the preinfusion period (days 130-132; Fig. I). However, during the treatment period ( $132-137$ days), progesterone concentrations in the indomethacin-treated group 
decreased significantly $(P<0.001)$ as shown by ANOVA, although SNK analysis failed to detect any differences between these time points. Further analysis using the test of least significant difference (LSD) revealed that the mean progesterone concentration on day 137 in the indomethacin-infused animals was significantly lower than mean progesterone concentrations on or before day 134. By the end of the infusion (day 137), the progesterone concentrations between the two groups were significantly different $(P<0,02$; Student's $t$ test). A further decrease in progesterone concentrations in the indomethacintreated group occurred on day 144, reflecting the onset of luteal regression. In contrast, no significant changes in progesterone concentrations were observed in the vehicle-infused group until day 147. Analysis of the gestational age of all goats at the time of delivery revealed that the mean day of labour between the two treatment groups (indomethacin, $144.3 \pm 0.76$ days; vehicle, $148 \pm 0.41$ days) was significantly different $(P<0.007)$. Labour occurred on, or before, day 146 of gestation in the indomethacin-treated group and on, or after, day 147 of gestation in the vehicle-treated group. There was no overlap of the day of labour between the two groups.

Plasma concentrations of $\mathrm{PGE}_{2}, \mathrm{PGF}_{2 \pi}$ and PGFM in the uterine vein are plotted against gestational age (Fig. 2). In the preinfusion period, there was no difference between the two groups in the concentrations of these prostaglandins. The infusion of indomethacin resulted in a significant decrease in $\mathrm{PGE}_{2}$ concentrations $\left(P<0.001\right.$ ); the $\mathrm{PGE}_{2}$ concentrations returned to preinfusion concentrations by 2 days after stopping the infusion. During the indomethacin infusion, the concentrations of $\mathrm{PGE}_{2}$, but not $\mathrm{PGF}_{2 \alpha}$ or PGFM, in the two groups were significantly different $(P<0.003)$. After the infusion of indomethacin was stopped, the plasma concentrations of PGFM gradually increased before undergoing a preparturient surge on day 144 , which coincided with a similar significant increase in plasma concentrations of $\mathrm{PGF}_{2 a}$ (Fig. 2) and a significant decrease in plasma concentrations of progesterone (Fig. I). In contrast, no changes in prostaglandin concentrations were observed during this time in the vehicle-infused animals.

\section{Discussion}

The present studies suggest that a product(s) of the cyclooxygenase pathway is involved in maintaining progesterone concentrations during late gestation in goats but they do not help in identifying which prostanoid(s) is involved. However, $\mathrm{PGE}_{2}$, a known luteotrophin (Liggins and Thorburn, 1994), is produced in large amounts by the caprine placenta (Ford et al., 1992) and is abundant in the arterial and uterine venous plasma during late gestation. Presumably, the plasma concentrations in the ovarian artery are higher than in the systemic arterial plasma because of countercurrent transfer of $\mathrm{PGE}_{2}$ from the utero-ovarian vein. The marked and persistent decrease in plasma $\mathrm{PGE}_{2}$ concentrations over the infusion period appears the most likely explanation for the decrease in progesterone secretion by the corpus luteum. However, this does not explain why progesterone concentrations remained low, despite the return of $\mathrm{PGE}_{2}$ to normal values, after cessation of the indomethacin infusion. The gradual increase in PGFM concentration suggests that the luteolytic mechanisms may have already been initiated and were irreversible.

The mechanism by which $\mathrm{PGE}_{2}$ maintains luteal function is unclear. Like $\mathrm{LH}, \mathrm{PGE}_{2}$ stimulates progesterone secretion and cAMP production by bovine luteal cells in vitro (Speroff and Ramwell, 1970; Marsh, 1971). $\mathrm{PGE}_{2}$ also increases progesterone synthesis and mRNA encoding $3 \beta$-hydroxysteroid dehydrogenase ( $3 \beta$-HSD) in granulosa cells from prepubertal pigs in a dose-dependent manner (Li et al., 1992). Li et al. (1992) conclude that $\mathrm{PGE}_{2}$ regulates granulosa cell function, in part, by altering the transcription or stability of mRNA encoding $3 \beta-H S D$.

It seems, therefore, that $\mathrm{PGE}_{2}$, together with $\mathrm{LH}$ (derived from the matemal pituitary) and possibly placental lactogen form a luteotrophic complex during late pregnancy in goats (Liggins and Thorburn. 1994), and the removal of any of the components (for example, LH; Malecki et al., 1987) causes a decrease in plasma progesterone concentrations and may lead to premature labour. Studies in both sheep and goats show that progesterone suppresses the release of $\mathrm{PGF}_{2 \alpha}$ from the maternal placenta and endometrium and that a prolonged decrease in progesterone concentrations, induced by the adminis-

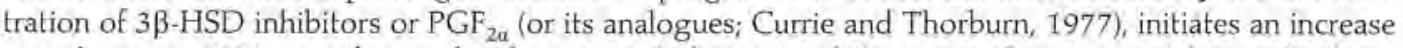
in endogenous PGF $_{2 a}$ production by the maternal placenta and the onset of premature labour (Thorburn et al, 1972; Currie and Thorburn, 1977; Liggins and Thorburn, 1994). A similar situation appears to 


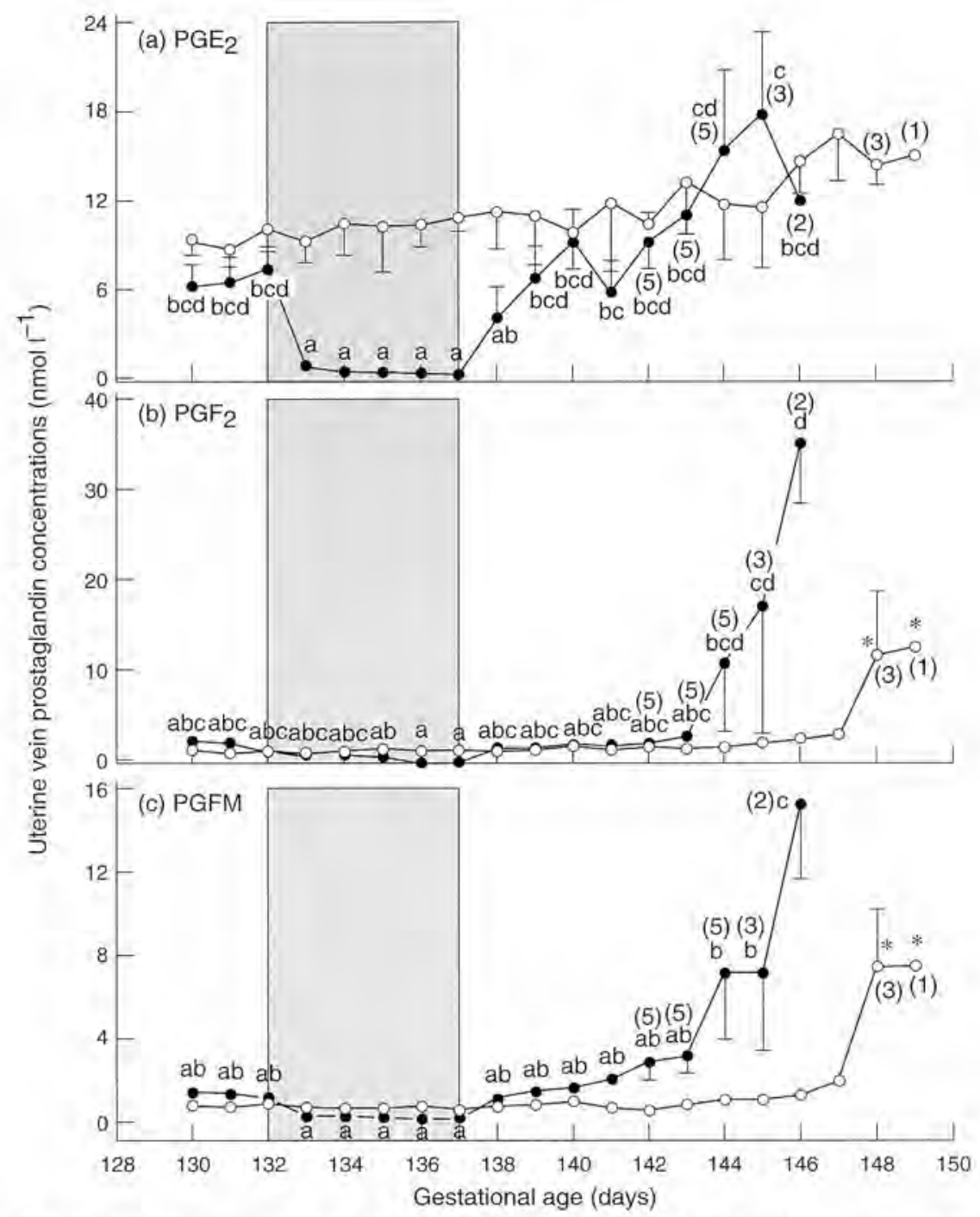

Fig. 2. Plasma concentrations of (a) $\mathrm{PGE}_{2}$ (b) $\mathrm{PGF}_{34}$ and (c) PGFM in the uterine vein of indomethacin- $(\bullet, n=6$ except where indicated due to parturition) and vehicle- $(0, n=4$ except where indicated due to parturition) infused animals. Values with different letters ( $a, b$, c, d) or symbols $(* * *)$ are significantly different $(P<0.05)$. The shaded area between day 132 and day 137 indicates the period of infusion.

occur in the present experiments. The small, prolonged decrease in progesterone concentration achieved during the indomethacin infusion, which apparently removed the luteotrophic support of $\mathrm{PGE}_{2}$, seemed to be adequate to stimulate uterine $\mathrm{PGF}_{2 a}$ production (as judged by the increase in PGFM concentrations). $\mathrm{PGF}_{2 \alpha}$ concentrations in the uterine vein did not increase between day 137 and day 143 , suggesting that most $\mathrm{PGF}_{2 \alpha}$ produced in the uterus was metabolized to PGFM. It appears that insufficient $\mathrm{PGF}_{2 a}$ to induce corpus luteum regression would have reached the corpus luteum by the countercurrent pathway. However, the decrease in progesterone production by the corpus luteum resulted in an increase in the oestrogen:progesterone ratio, and presumably caused an increase in oxytocin receptors in the placenta and possibly the corpus luteum. A local increase in $\mathrm{PGF}_{2 \alpha}$ synthesis in the corpus luteum may have been important in initiating premature luteal regression. 


\section{References}

Burgess KM, Ralph MM, Jenkin G and Thorburn GD (1990) Effect of oxytocin and estradiol on uterine prostaglandin release in nonpregnant and early-pregnant ewes Biology of Reproduction $42 \quad 822-833$

Currie WB and Thorburn GD (1977) Parturition in goats: studies on the interactions between the foetus, placenta, prostaglandin $\mathrm{F}$ and progesterone before parturition, at term or at parturition induced prematurely by corticotrophin infusion into the foetus lowmal of Endocrinology $73263-278$

Deayton JM, Young IR and Thorburn GD (1993) Early hypophy. sectomy of sheep fetuses: effects on growth, placental steroidogenesis and prostaglandin production Journal of Reproduction and Feritity 97 513-520

Ford MM, Burgess KM, Young IR and Thorburn GD (1992) $\mathrm{PGE}_{2}$ secretion by the goal placenta. Proceedings $24 \mathrm{th}$ Annual Conference of the Australian Society for Reproductive Biology (Adelaide) p 133 (Abstract)

Ford SP and Christenson LK (1991) Direct effects of oestradiol$17 \beta$ and $\mathrm{PGE}_{2}$ in protecting pig corpora lutea from a luteolytic dose of $\mathrm{PGF}_{2 \mu}$ Journal of Reproduction and Fertility $93203-209$

Henderson KM, Scaramuzzi RJ and Baird DT (1977) Simultaneous infusion of prostaglandin $\mathrm{E}_{2}$ antagonizes the luteolytic action of prostaglandin $\mathrm{F}_{2,}$ in vivo Endocrinology 72 379-383
Li X-M, Juorio AV and Murphy BD (1992) Prostaglandins $\mathrm{F}_{20}$ and $\mathrm{E}_{2}$ differentially alter transcription of steroidogenic enzymes in porcine granulosa cells in vitro Biology: of Reproduction Supplenient P 125 Abstract 300

Liggins GC and Thorburn GD (1994) Initiation of Parturition. In Marshall's Physiology of Reproduction Vol. 3 Part 2 p 891 Ed. GE Lamming. Chapman and Hall, London

Malecki J, Jenkin G and Thorburn GD (1987) Passive immuniz. ation of pregnant goats against ovine LH Journal of Endocrinology $114 \quad 413-436$

Marsh JM (1971) The effect of prostaglandins on the adenyl cyclase of the bovine corpus luteum Annals of the New York Academy of Sciences $180416-425$

Mitchell MD, Flint APF, Robinson JS and Thorburn GD (1978) ln vilro production of prostaglandins by intrauterine tissues from pregnant goats Journal of Reproduction and Fertility $\mathbf{5 2}$ $151-152$

Speroff L and Ramwell PW (1970) Prostaglandin stimulation of in vitro progesterone synthesis Journal of Clinical Endocrinology and Metabolism 30 345-350

Thorburn GD, Nicol DH, Bassett JM, Shutt DA and Cox RI (1972) Parturition in the goat and sheep changes in corticosteroids, progesterone, oestrogens and prostaglandin F Journal of Reproduction and Fertility Supplement 16 61-84 